\title{
Ser professor universitário: identidades construídas entre aspectos de satisfação e insatisfação profissional
}

\author{
Fábio Machado Ruza \\ Universidade Federal de São Carlos \\ Santuza Amorim da Silva \\ Karla Cunha Pádua \\ Universidade do Estado de Minas Gerais
}

\section{Resumo}

Neste artigo, sintetizam-se resultados de uma pesquisa que analisou os elementos constituintes das identidades profissionais dos professores da Universidade do Estado de Minas Gerais, triangulando dados de questionários e entrevistas narrativas aplicadas aos docentes, com a análise de documentos. Os dados revelaram que, na instituição pesquisada, as identidades profissionais se constroem, contraditoriamente, entrecruzando insatisfação profissional, decorrente da precariedade das condições de trabalho, e satisfação profissional relacionada ao ambiente de trabalho e à autonomia profissional.

Palavras-chave: Professor universitário. Identidade profissional. Trabalho docente. Organização do trabalho. Satisfação profissional. 


\section{To be a university professor: identities built between aspects of professional satisfaction and dissatisfaction}

This paper summarizes results of research analyzing the constituent elements of professional identities of professors at the State University of Minas Gerais, triangulating data from questionnaires and interviews conducted in narrative format, with documental analysis. The data revealed that, in the institution researched; professional identities are built contradictorily, interlacing professional dissatisfaction, due to precarious working conditions, and professional satisfaction, resulting from the work environment and professional autonomy.

Keywords: Professor. Professional identity. Teaching Work. Organization. Professional Satisfaction.

\section{Ser profesor universitario: identidades construidas entre aspectos de satisfacción e insatisfacción profesional}

En este artículo se sintetizan resultados de un estudio que analizó los elementos constitutivos de las identidades profesionales de los profesores de la "Universidade do Estado de Minas Gerais", triangulando datos de los cuestionarios y entrevistas narrativas aplicadas a los docentes, con el análisis de documentos. Los datos revelaron que en la institución investigada las identidades laborales se construyen, contradictoriamente, entrecruzando insatisfacción laboral, debido a la precariedad de las condiciones de trabajo, y la satisfacción profesional relacionada con el ambiente de trabajo y con la autonomía profesional.

Palabras-clave: Profesor universitario. Identidad profesional. Trabajo docente. Organización del trabajo. Satisfacción profesional. 


\section{Introdução}

Este artigo apresenta resultados de uma pesquisa que analisou os elementos que compõem o processo de construção das identidades profissionais do professor universitário, a partir do estudo de caso da Faculdade de Educação, campus de Belo Horizonte, da Universidade do Estado de Minas Gerais (FaE/CBH/UEMG).

A identidade é um fenômeno que deriva da dialética entre o indivíduo e a sociedade; por este motivo, ela se constrói a partir das interações que a "pessoa" (self) estabelece com o social (outrem). Neste caso, tais relações podem ocorrer no desempenho das atividades profissionais, nas interações sociais e no exercício de determinados papéis nos grupos de que participa. As identidades profissionais construídas nas relações entre o "eu" e o "outro" são, pois, complexas, múltiplas e dinâmicas, sendo continuamente construídas, desconstruídas e reconstruídas a partir de novas experiências como pessoa e professor. (Berger; Luckmann, 2002; Dubar, 2005)

A pesquisa apontou que as identidades profissionais do professor da $\mathrm{FaE} / \mathrm{CBH} /$ UEMG recebem influência de uma multiplicidade de elementos, tais como: história de vida do professor, atividades profissionais que compõem o trabalho docente, relação disciplinar que permeia este ofício e o tipo de carreira desenvolvida pelo professor - de pesquisador ou de ensino (Ruza; Silva; Pádua, 2013). Todavia, para este artigo, o foco de análise recairá na influência que a organização de trabalho, compreendida pelas condições materiais de trabalho, pelo ambiente e pela autonomia profissional, desempenha no trabalho e na construção identitária do professor da $\mathrm{FaE} / \mathrm{CBH} / \mathrm{UEMG}$, de modo a permitir que as identidades docentes se constituam em meio a relações entre aspectos de satisfação e insatisfação profissional.

A universidade pública brasileira se insere num contexto caracterizado pela predominância da esfera financeira de acumulação capitalista (mundialização do capitall e pela Reforma do Estado, pautada por diretrizes neoliberais. Tal contexto promove a mercantilização do ensino superior público, traduzido pela consolidação de um modelo de ciência instrumental e de universidade pragmática, cuja intenção consiste em atender às necessidades do capital financeiro-industrial (Sguissardi; Silva Júnior, 2009). Repercute também na adoção de um modelo de gestão gerencial (Gaulejac, 2007), anteriormente restrito a empresas privadas, e, principalmente, na institucionalização do produtivismo acadêmico, que se configura na hipervalorização da pesquisa e da produção acadêmico-científica, tendendo, por vezes, a desconsiderar a qualidade e relevância social de tais produções (Sguissardi; Silva Júnior, 2009; Silva, 2013). Embora estes acontecimentos venham aos poucos transformando o perfil da UEMG com o objetivo de institucionalizar 
uma "sociabilidade produtiva", algumas especificidades institucionais, como a situação de precariedade das condições de trabalho e a centralidade do ensino decorrente de sua história institucional, contribuem para que estas influências ocorram mais lentamente e afetem prioritariamente os docentes com doutorado que atuam na pós-graduação, sobretudo pelas pressões por produtividade acadêmica propagadas no sistema Capes $^{1}$ de avaliação da pós-graduação e nos critérios das agências de fomento à pesquisa.

A FaE/CBH/UEMG vêm aos poucos recebendo influências de um modelo de gestão denominado "Choque de Gestão", que possui características gerencialistas, cujo objetivo está em reduzir custos e ampliar a eficiência das instituições estaduais mineiras. Com base em uma de suas ações, o "Acordo de Resultados", são formulados e avaliados parâmetros de desempenho individual e institucional, atrelando o cumprimento das metas de produtividade à obtenção de recompensas financeiras, como a bonificação salarial (Vilhena; Martins; Marini, 2006). Contudo, as pressões dos procedimentos de avaliação do trabalho ainda são pouco sentidas pelos docentes em face de as instâncias administrativas da instituição se colocarem como mediadoras entre os interesses dos professores e do Estado, fornecendo a eles a possibilidade de avaliar o seu trabalho. Concomitantemente, veremos que a construção de um ambiente de trabalho e de uma autonomia profissional serão aspectos de satisfação relatados pelos professores, os quais se constroem em face da gestão democrática e colegiada e da construção coletiva das instâncias da universidade.

A UEMG presencia um processo de precarização das condições materiais de trabalho, existente em muitas universidades estaduais criadas a partir da década de 1980:

Muitas das jovens universidades estaduais criadas nesse período [décadas de 1980 e 1990] já nasceram sob a regra da precarização, exibindo formas "criativas" de contratação. Além dos contratos temporários e efetivos baseados em horas-aula (pagamento por aula e ausência de Plano de Carreiral como é o caso da Fundação Estadual de Alagoas, tem sido prática corrente o recurso às 'bolsas de pesquisa' e 'adicionais' por atividade de extensão como forma de remuneração docente (Universidade Estadual do Piauí e as 4 universidades estaduais da Bahia). (Bosi, 2007, p. 1509-1510)

Em conformidade com as universidades analisadas por Bosi (2007), a UEMG foi criada em 1989 e partilha de semelhante realidade de precarização institucional, 
configurada por contratos de trabalho fragmentados entre docentes da categoria "efetivados"; plano de carreira precarizado; baixa remuneração salarial; e infraestrutura predial alugada e adaptada ao funcionamento da instituição. Nestas condições, parte dos professores encontram dificuldades para se dedicarem plenamente às atividades que compõem o ofício do "professor universitário" e construírem projetos profissionais na universidade, o que sem dúvida influencia negativamente a sua identidade profissional. Contudo, tais aspectos de precarização institucional são contrabalanceados com a existência de um bom ambiente de trabalho e de uma autonomia profissional. São justamente as relações entre os fatores de satisfação e insatisfação profissional que serão, a partir de agora, focalizadas na análise da construção das identidades profissionais do docente da $\mathrm{FaE} / \mathrm{CBH} / \mathrm{UEMG}$.

No entanto, antes de adentrar na análise propriamente dita, é importante ressaltar os percursos metodológicos da pesquisa. Trata-se de uma pesquisa qualitativa do tipo estudo de caso (Yin, 2009), que examinou a realidade da FaE/ $\mathrm{CBH} /$ UEMG. Como fontes de evidências, procedeu-se à análise de documentos institucionais e legislações sobre o ensino superior brasileiro, à aplicação de questionários a 59 professores, que representam $53,6 \%$ do total de 110 docentes estáveis, e à realização de cinco entrevistas orais, a partir da modalidade narrativa (Flick, 2004; Silva; Pádua, 2010), com professoras efetivadas (estáveis): uma doutora, uma doutoranda, duas mestras e uma especialista. Entrevistou-se, também, uma professora considerada informante privilegiada (Silva; Silva; Junckes, 2009), de modo a obter informações mais gerais sobre a instituição e o corpo docente, para ajudar no aperfeiçoamento do instrumento da entrevista narrativa. Estas fontes de evidências foram trianguladas e os dados foram analisados em conformidade com os objetivos da pesquisa, centrando-se na análise do trabalho e dos elementos constituintes das identidades profissionais dos professores. Por fim, a pesquisa foi submetida à apreciação e aprovação do Comitê de Ética em Pesquisa, e todos os participantes preencheram os termos de consentimento livre esclarecido (TCLE), com o anonimato das entrevistadas garantido, mediante o uso de pseudônimos.

\section{As condições de trabalho na FaE/CBH/UEMG}

As condições de trabalho na FaE/CBH/UEMG caracterizam-se por uma situação de precarização, advinda de uma série de fatores, como: flexibilização dos contratos e da carga horária de trabalho, baixa remuneração salarial, plano de progressão de carreira ineficiente e carência de infraestrutura física adequada. Tais aspectos serão pormenorizados, pois se constituem como elementos de insatisfação que 
repercutem no trabalho e na construção da identidade profissional do docente.

0 primeiro elemento a se destacar remonta à análise feita por Bosi (2007) de que as "novas" universidades estaduais foram construídas sob a orientação de formas flexíveis e precarizadas de contratos de trabalho, bem ao espírito de uma gestão de caráter gerencial. A FaE/CBH/UEMG inscreve-se nesta realidade ao apresentar uma situação funcional dos docentes bastante heterogênea, em que somente $18,7 \%$ eram efetivos e a maioria $(62,7 \%)$ era efetivada ${ }^{2}$ - categoria que se tornou estável com a aprovação da Lei Complementar n. ${ }^{0}$ 100, de 05/11/2007. Ademais, 6,8\% possuíam dois contratos de trabalho: efetivado e designado (temporário) e 10,2\% não relataram sua situação funcional nos questionários.

0 baixo índice de professores efetivos e o fato de os efetivados pela Lei Complementar n. ${ }^{0} 100$, de 05/11/2007, não poderem ampliar sua carga horária de trabalho contribuíram para que, no momento da pesquisa, houvesse apenas $32,2 \%$ de professores com carga horária de 40 horas/aula. As demais conformações se apresentaram bastante heterogêneas: 20 horas/aula (15,3\%); menos de 20 horas/ aula (10,2\%); entre 21 horas/aula e 39 horas/aula (34\%); mais de 40 horas/aula $(6,8 \%)$; e $1,7 \%$ deixou de responder.

A flexibilização dos contratos e a fragmentação da carga horária de trabalho foi denunciada pela totalidade dos docentes entrevistados como situações de insatisfação profissional que dificultam ao professor construir uma identificação com a UEMG e com a carreira acadêmica, conforme se elucida nestes dois relatos:

A situação na UEMG é difícil. Quer dizer, uma das coisas que acho que inviabiliza muito a construção desta universidade e da identidade profissional do professor é a fragmentação da carga horária do docente. 0 profissional que trabalha aqui não tem muitas condições de construir uma identidade de professor da UEMG porque ele é horista e trabalha seis, dez, doze horas semanais. Assim, como é que ele se vincula? Como é que ele veste a camisa? Como é que ele respira isso aqui? Não tem jeito, pois, muitas vezes, ele vem, dá sua aula e vai embora. (Ana, 2011)

As coisas estão caminhando devagar pelas limitações das condições de trabalho. Por exemplo, um professor efetivado com seis horas aula ainda hoje não pode aumentar sua carga horária. E, mesmo depois de lutarmos bastante com o governo, não conseguimos mudar isto. Então, como ele pode fazer pesquisa? Não pode, né? Como é que se exige produção dele? Não se exige. (...) Vou te contar que da forma que foi feita a efetivação foi uma fatalidade, porque as pessoas precisam trabalhar em outros lugares e ficam insatisfeitas, pois acham que estão trabalhando de graça. (Paula, 2011)

2. Esta categoria contempla os 96 mil professores da rede básica de educação e universitários que eram designados (temporários) e que foram efetivados (transformados em profissionais estáveis) a partir da aprovação da Lei Complementar n. ${ }^{0}$ 100, de 05/11/2007 
As narrativas das professoras esclarecem que a fragmentação da carga horária de trabalho repercute de forma negativa no desenvolvimento do trabalho, pois limita a possibilidade de o docente dedicar-se integralmente às atividades que compõem a carreira acadêmica: ensino, pesquisa, orientação, produção acadêmica, extensão, administração e representação. Essa situação dificulta a construção de elementos de identificação com a FaE/CBH/UEMG e com a carreira acadêmica, pois este docente possui poucas condições objetivas para participar dos espaços de discussão e deliberação da universidade, realizar pesquisas e produzir artigos e fica insatisfeito com a instituição. Acrescenta-se, ainda, a dificuldade em construir projetos de vida e de carreira na universidade e a sobrecarga de trabalho, advinda da necessidade de exercer uma dupla jornada de trabalho.

A respeito dessa sobrecarga, uma entrevistada ressaltou seu esgotamento profissional por trabalhar em dois locais distintos:

Trabalhar na Rede Básica e no Ensino Superior é difícil, porque são dois locais e duas exigências muito diferentes. Por isto, eu tenho achado muito difícil conciliá-los e, às vezes, acho que terei que fazer uma opção, sabe? (Patrícia, 2011)

No geral, a literatura (Bosi, 2007; Maués; Mota Júnior, 2011; Sguissardi; Silva Júnior, 2009; Silva, 2013) mostra que as universidades públicas com longa "tradição em pesquisa" vivenciam um processo de intensificação de trabalho. Para isso influenciaram fatores como: metas de produtividade formuladas pela Capes e pelas agências de fomento à pesquisa; política de "otimização" dos recursos humanos (professores), de modo a elevar a concentração de estudantes por docente; e o excesso de demandas multiformes de trabalho no ensino, na pesquisa, na extensão, bem como nas atividades administrativas e representativas. No entanto, a intensificação de trabalho na FaE/CBH/UEMG se apresenta notadamente pela dupla jornada, advinda, prioritariamente, da fragmentação da carga horária, ainda que sejam notados com menor intensidade os efeitos das demandas multiformes de trabalho e da pressão por produção, sobretudo entre os professores doutores que atuam na pós-graduação.

As consequências nocivas da fragmentação da carga horária de trabalho são agudizadas por a remuneração salarial ser inferior à maioria percebida nas universidades públicas e por sofrer bastante variação em decorrência da carga horária e da titulação acadêmica ${ }^{3}$. Os professores em sua maioria $(55,9 \%)$ acreditam que o seu salário é ruim, seguido por 35,6\% que o consideram regular. Apenas $6,8 \%$ o julgam bom e 1,7\% não respondeu. A despeito desta insatisfação dois relatos são elucidativos:

3. Na época da pesquisa, havia $20,3 \%$ de doutores, $59,35 \%$ de mestres e $20,35 \%$ de especialistas. 
O salário está defasado em relação à carreira de magistério no ensino superior. (Questionário, 2011)

Aqui há uma grande sensação de insegurança para o professor, porque o salário que recebemos não é bom e fica pior para aquele que não tem sua carga horária completa. Só temos as gratificações ao salário. Por isto, muita gente está saindo daqui porque fica inseguro, entendeu? (...) Que perspectiva de futuro tem o professor que, quando aposenta, tem perda de vencimento? Nenhuma, né? Isto é um entrave grande à produtividade e afeta bastante o trabalho e o subjetivo do professor. (Paula, 2011)

Ainsatisfação do professor quanto ao salário advém de ele ser comparativamente inferior ao praticado pela maioria das universidades públicas, sofrer grande variação em decorrência da fragmentação da carga horária de trabalho do professor e ser constituído de gratificações não incorporáveis à aposentadoria.

Concomitantemente ao descontentamento com a carga horária de trabalho e a remuneração salarial, os dados coletados revelaram elevado índice de insatisfação com o plano de carreira, haja vista que $49,2 \%$ dos docentes o consideram ruim, $35,6 \%$ regular, $8,5 \%$ bom e $6,8 \%$ não opinaram. A insatisfação com o plano de progressão de carreira decorre de sua má aplicabilidade tornar-se um empecilho à ascensão vertical pela titularidade acadêmica:

Acho que necessitamos urgentemente discutir um plano de progressão, que, em minha opinião, praticamente inexiste. (Questionário, 2011)

Nós ficamos um tempão sem ter nosso plano de carreira na universidade. Depois, fizeram um plano que não considerava como se nós fôssemos uma universidade. Por exemplo, aí entra o meu caso: terminei meu doutorado em 2007. Ou seja, no próximo ano eu serei doutora sênior e a universidade ainda não me posicionou como doutora. (...) Sabe, são essas maluquices, como o plano de progressão que ninguém acredita e que é triste. $E$, realmente, se a gente pensar, dá muita raiva e não dá vontade de... Enfim, a gente desiste, né? Mas essas coisas estão melhorando, pelo menos eu acredito. (Maria, 2011)

No caso da FaE/CBH/UEMG, o plano de carreira, ao invés de servir como elemento de motivação para o corpo docente elevar sua titulação e construir vínculos de pertencimento institucional, tornou-se fator de descontentamento por não atender as especificidades do magistério superior. Zabalza 12004, p. 136) considera que, para que “tenha efeitos de estímulo e enriquecimento da autoestima [...], é necessário que a carreira acadêmica não seja linear, mas que haja sucessivas progressões ou melhoras", que não pode estar "vinculada apenas 
a critérios burocráticos ou a simples critérios de antiguidade", mas é "necessário que esse progresso esteja associado a méritos profissionais". E o plano de carreira vigente no momento da pesquisa priorizava a ascensão por tempo de serviço, dificultando, por uma série de mecanismos, o progresso pela titulação acadêmica.

A UEMG, como foi exposto até o momento, possui muitos pontos de similaridades com as universidades estaduais analisadas por Bosi (2007), haja vista que ela apresenta formas flexíveis e precarizadas de contratação, baixa remuneração salarial e plano de carreira insatisfatório. Outra similaridade do caso UEMG com as universidades estaduais criadas nas décadas de 1980 e 1990, sob a via da precarização, refere-se à inadequação da infraestrutura física ao funcionamento da universidade. No tocante a isto, o autor ressalta:

A grande maioria das universidades estaduais criadas desde o final da década de 1980 carece de infraestrutura para atividades de pesquisas. Algumas sequer possuem instalações próprias, mas funcionam em prédios adaptados. (Bosi, 2007, p. 1510)

Realidade semelhante ocorre na FaE/CBH/UEMG, pois atualmente ela está instalada em um prédio vertical com doze andares, alugado, pequeno e adaptado ao funcionamento da universidade, situação que dificulta aos docentes desenvolverem plenamente as atividades que compõem seu trabalho na universidade e se socializarem com os professores, alunos e funcionários. Em relação a isto, dois relatos elucidam esta realidade:

Considero que a falta de infraestrutura interfere na minha identidade (...) porque aqui não temos salas para trabalhar, a biblioteca é pequena e (...) até no que se refere a tecnologia as coisas são limitadas, pois só há quatro salas de multimídia para um prédio inteiro utilizar. (Patrícia, 2011)

0 espaço físico tem que ser melhorado urgentemente, porque a sala dos professores é muito pequena e você acaba não tendo privacidade. Isto interfere nas nossas condições, pois mistura muito a esfera do público e do privado, visto que o espaço de trabalho é na Instituição. (...) Na UEMG você estende sua jornada de trabalho no espaço privado da sua casa e se intensifica em termos de horas e de atividades que poderiam às vezes ser desenvolvidas na faculdade e que não ocorrem pela limitação das condições. (...) Além disso, muitas vezes, você só encontra o colega no elevador, sendo que, se fosse numa estrutura horizontal, você teria mais momentos de contato. (Alice, 2011)

A carência de uma infraestrutura adequada dificulta ao docente desenvolver todas as dimensões de seu trabalho na universidade, precisando fazê-lo no âmbito 
privado, condição que contribui para se perder a referência das horas trabalhadas, estendendo a jornada de trabalho. A infraestrutura do prédio desfavorece, ainda, os espaços de convívio social e as oportunidades de trocas profissionais, dificultando a criação de vínculos de pertencimento institucional e de socialização profissional, tão necessários conforme Dubar (2005) sinaliza para a construção identitária.

Entretanto, tais possibilidades de interação e pertencimento institucional são construídas, em grande medida, na participação em órgãos de representação colegiada, em atividades de trabalho coletivo previstas na organização curricular da instituição, no movimento de reivindicação dos professores em prol de melhorias nas condições de trabalho e nas instâncias de funcionamento da universidade: Centro de Pesquisa, Centro de Extensão, Comitê de Ética e Comitê de Reformulação Curricular, conforme enfatizam, no relato, duas professoras:

A nossa trajetória na Instituição é historicamente marcada por lutas do corpo docente (...) [Neste processo] a minha trajetória é marcada pela procura por qualificação e pelo engajamento no movimento dos professores por melhores condições de trabalho, pois, no caso da UEMG, nós ainda temos muito a conseguir, porque temos problemas estruturais muito sérios, como falta de espaço para estudo, falta de equipamento e falta de estrutura para pesquisa. Estas condições e as reivindicações fazem parte da nossa identidade profissional de docente do ensino superior e da UEMG. (Alice, 2011)

Gosto muito de trabalhar aqui e tenho muito prazer nas coisas que faço mesmo com todas as dificuldades de condições de trabalho que enfrento. (...) Eu não faço nenhuma crítica, mas é normal as pessoas terminarem o doutorado e irem para outro local onde as coisas já estão prontas, onde tenham uma condição para trabalhar melhor do que esta, mas eu não penso assim e quero continuar aqui. Tem horas que a gente tem motivação de construir, outras horas a gente tem vontade de desistir, porque é pesado lutar e construir a Universidade, né? Sabe, o tempo inteiro você está sendo convidado a essa construção. Isso é interessante, por um lado, muito interessante, mas, por outro lado, muitas vezes, eu acho que podia ser um pouquinho mais fácil para gente, né? (Ana, 2011)

Trabalhar na melhoria da universidade não é tarefa fácil e gera grande sobrecarga de trabalho. Todavia, a ação prática e construtiva do professor diante da precariedade das condições de trabalho não só minimiza os elementos de insatisfação, mas, em certa medida, pode convertê-los, ainda que não plenamente, em fator de satisfação profissional. Esta condição é possível, especialmente por existir uma dinâmica de contribuição-retribuição (Dejours, 2004; 2004a) na FaE/ $\mathrm{CBH} / U E M G$, em que os docentes possuem liberdade para expressar suas opiniões e agir construtivamente, obtendo o reconhecimento dos pares, funcionários 
e alunos nesta ação. Com isto, os professores não só constroem vínculos de afinidade e solidariedade profissional, mas edificam uma descoberta exitosa de si e um sentido social ao trabalho que realizam - fatores fundamentais para a constituição identitária e para ressignificação da insatisfação em motivação e prazer profissional.

As lutas dos professores são permanentes e constituem, conforme relato da entrevistada acima, a própria identidade do professor da UEMG. Contudo, para além das conquistas voltadas ao funcionamento da universidade, cite-se, por exemplo, a institucionalização de centros de pesquisa e extensão que permitiram a aquisição de bolsas de iniciação científica. No entanto, as conquistas provenientes do poder público são poucas e, às vezes, não ocorrem conforme a reivindicação dos docentes. Pode-se mencionar, nesta direção, a mudança da FaE/CBH/UEMG - que antes funcionava no prédio do Instituto de Educação de Minas Gerais (IEMG), dividindo o espaço físico com alunos da educação básica - para um prédio pequeno, alugado, que continua não atendendo às necessidades de funcionamento de uma universidade. Historicamente, existem discussões sobre o projeto de construção do campus da UEMG em Belo Horizonte, mas, só em 2014, houve sinalizações para o início das obras de construção do prédio destinado à FaE/CBH/UEMG.

A própria efetivação dos professores pela Lei Complementar n. ${ }^{0} 100$, de 05/11/2007, foi uma conquista parcial, senão às avessas, pois, motivado pela necessidade de o Estado regularizar as pendências com o Ministério da Previdência Social (MPS), com intuito de obter o Certificado de Regularização Previdenciária (CRP), que permitiria firmar convênios e receber recursos do governo federal, o governo de Minas Gerais elaborou um estudo orçamentário que concluiu ser financeiramente mais viável efetivar os servidores da educação designados do que pagar as contribuições previdenciárias atrasadas. 0 fato de o poder público ter centrado esta decisão unicamente em aspectos econômicos impossibilitou a ampliação da carga horária de trabalho dos docentes que foram efetivados por esta lei, que causou, ainda, recentes prejuízos aos professores, pois, em 28 de março de 2014, o Supremo Tribunal Federal (STF) julgou ser inconstitucional a Lei Complementar n. ${ }^{0} 100$, de 05/11/2007. Com isto, a maior categoria funcional da UEMG - professores efetivados - novamente torna-se professores designados (temporários), retornando à situação de precariedade e de instabilidade profissional. Esta condição é nociva para a continuidade do desenvolvimento profissional e o bem-estar dos professores e de suas famílias, além de dificultar a continuidade do desenvolvimento da própria universidade, especialmente porque atualmente ela é composta em sua maioria por professores temporários. Ainda que se realizem concursos públicos para docente efetivo, a identidade institucional e a continuidade de alguns projetos na UEMG podem ser afetados, com a possibilidade 
de haver grande substituição de professores em pouco tempo.

Nos meses subsequentes à realização desta pesquisa, viu-se a concretização jurídica de importantes conquistas em face da mobilização dos docentes e da atuação da reitoria. Todavia, por a Lei Complementar n. ${ }^{0} 100$, de 05/11/2007, ter recentemente se tornado inconstitucional, tais conquistas foram reduzidas, prioritariamente, a pequena parcela de professores efetivos. Destas conquistas, destaca-se: a promulgação das leis n.os 20.336, de 2/7/2012, e 20.591, de 29/12/2012, e dos decretos n.os 46.024, de 16/8/2012, e 46.056, de 3/10/2012. Juntos, eles promoveram sensível melhora na remuneração e no plano de carreira dos professores ao incorporar uma série de benefícios como, por exemplo, licença para qualificação docente sem perda de vencimentos, Gratificação de Escolaridade, Desempenho e Produtividade Individual e Institucional (GEDIMA), Gratificação de Incentivo à Docência (pó de giz), Gratificação de Desempenho da Carreira de Professor de Educação Superior (GDPES) e Adicional de Dedicação Exclusiva (DE), e ao incorporar alguns deles também aos proventos de aposentadoria e pensão.

Em face da situação apresentada, constata-se que a precariedade das condições materiais é o principal elemento de insatisfação profissional. Todavia, a resposta ativa e construtiva dos professores diante desta realidade possibilita unificá-los em prol de um ideal comum e converter, ainda que parcialmente, esta insatisfação em satisfação profissional, efetivada pela via do reconhecimento profissional e da construção de um sentido ao trabalho. Ademais, propicia algumas melhorias nas condições de trabalho que não são plenas em vista do pouco comprometimento do Estado com o ensino superior estadual.

\section{0 ambiente de trabalho e a autonomia profissional na FaE/CBH/UEMG}

0 ambiente de trabalho na FaE/CBH/UEMG é um importante elemento de satisfação profissional e se contrapõe ao descontentamento advindo da precariedade das condições de trabalho. Constatou-se que $81,4 \%$ dos docentes estão satisfeitos com o ambiente de trabalho (40,7\% ótimo e $40,7 \%$ bom); apenas $11,9 \%$ o consideram regular, e 5,1\% ruim. Não opinou 1,7\%. Acerca desta satisfação dois relatos são elucidativos:

A FaE/UEMG é uma instituição em que experimentei grande crescimento profissional. Gosto especialmente do perfil dos alunos e do clima de trabalho entre os colegas. 0 problema mais sério da instituição, do meu ponto de vista, é a situação funcional dos docentes. (Questionário, 2011) 
É um local que tenho autonomia didático-pedagógica e que me sinto respeitada por meus superiores, colegas e alunos. (Questionário, 2011)

Conforme os relatos evidenciam, o ambiente de trabalho na FaE/CBH/UEMG é caracterizado pelo bom relacionamento entre os professores, alunos e a gestão. A relação com os alunos é considerada positiva pela "quase totalidade" dos professores, já que $72,9 \%$ consideram sua relação ótima, $23,7 \%$ bom e apenas $1,7 \%$ ruim. Não respondeu 1,7\%. 0 bom relacionamento com os discentes, em certa medida, também está relacionado à identificação que os docentes possuem com o ensino: "eu gosto profundamente é de dar aula e sempre mantive uma boa relação com os alunos" (Ana). A identificação com o ensino, para além das trajetórias individuais de cada docente, possui alguns elementos de ordem coletiva, a saber: a origem da instituição no IEMG que desde 1906 formava professores e gestores para atuar na educação; a recente criação da universidade (1989); a atual consolidação da pesquisa e pós-graduação; a heterogeneidade de perfis profissionais e titulações acadêmicas entre os docentes; e a precariedade das condições de trabalho. (Ruza; Silva; Pádua, 2013)

A relação interpessoal entre os docentes, no geral, é positiva, especialmente porque $57,6 \%$ a consideram ótima, $35,6 \%$ boa; somente $6,8 \%$ o consideram regular. A boa relação entre os professores pode ser explicada pela UEMG ainda não ter adentrado plenamente na cultura do produtivismo acadêmico, em que se propaga um individualismo e competitividade entre os docentes por produção acadêmica, aos moldes do que ocorre na maior parte das instituições públicas com "tradição em pesquisa”. (Maués; Mota Júnior, 2011; Sguissardi; Silva Júnior, 2009; Silva, 2013)

0 bom relacionamento entre os docentes da FaE/CBH/UEMG é favorecido, ainda, pela existência de espaços de socialização profissional, criados por uma organização curricular que prevê oportunidades de trabalho coletivo, como as atividades de integração pedagógica (AIP ${ }^{4}$ e as aulas integradas ${ }^{5}$. Estes espaços e tempos escolares de trabalho coletivo, construídos a partir da mobilização dos professores, permitem-lhes construir afinidades profissionais, desenvolver outros trabalhos conjuntos e trocar conhecimentos. Ademais, é importante ressaltar que o envolvimento dos professores não se centrou exclusivamente na obtenção de melhorias nas condições materiais de trabalho, mas estendeu-se à

\footnotetext{
4. A AIP constitui uma disciplina semanal, que congrega professores e alunos de um núcleo formativo (turma) para que se conduza de forma integrada e coletiva a orientação de estágio, a elaboração da monografia e o desenvolvimento de atividades culturais e artísticas.

5. As aulas integradas são ministradas por professores de disciplinas diferentes que procuram integrar os conteúdos numa perspectiva interdisciplinar.
} 
democratização das instâncias de decisão na universidade, que anteriormente estavam concentradas com os "antigos" docentes efetivos:

Nossa luta não era só restrita à questão salarial, até porque muito pouco se conseguiu, mas ela também era muito marcada pela inserção em espaços de representação. Por exemplo, se hoje os professores efetivados, antigos designados, ocupam cargos importantes na chefia de departamentos e na Reitoria, isto ocorreu em função dessa luta dos professores, pois antes os professores efetivos concentravam todo o poder em si, e isto contribuiu para nossa identidade (...). Assim, vejo que o processo de democratização dos espaços está sendo histórica e diariamente construído. (Alice, 2011)

A conquista de espaços de decisão na UEMG contribuiu com a unificação da categoria de professores efetivados e proporcionou o estabelecimento de espaços de representação democrática. Estes dois fatores - a mobilização dos professores e a democratização dos espaços de representação democrática - contribuíram para tornar o ambiente de trabalho na universidade mais coletivo e dialógico, no lugar de prescritivo. Com isto, os docentes possuem maiores possibilidades de reinventar a organização de trabalho, obter reconhecimento profissional e construir vínculos de pertencimento institucional, solidariedade profissional e afinidades (Dejours, 2004; 2004a). Todavia, a existência de um bom ambiente de trabalho não isenta o fato de haver dissensos e conflitos esporádicos, até porque é por intermédio deles que a própria organização de trabalho se reconstrói.

Em certa medida, a própria democratização das instâncias de decisão e representação da universidade pode explicar o fato de parte significativa dos professores $(82,2 \%)$ estar satisfeita com os gestores da universidade $141,1 \%$ ótimo e $41,1 \%$ bom), seguido por $10,2 \%$ que o consideram regular e $1,7 \%$ ruim. Os próprios docentes consideram que os gestores (chefes de departamento, diretor da faculdade, etc.) procuram fazer a mediação entre os interesses do Estado e o dos professores. Cita-se como exemplo a oportunidade oferecida aos docentes para participar de seu processo avaliativo por meio da autoavaliação de alguns aspectos de seu trabalho, com objetivo de ressignificar o processo avaliativo e cumprir com as exigências do Acordo de Resultados empreendido pelo governo mineiro:

Eu tenho autonomia didático-pedagógica, mas, do ponto de vista da regulação do Estado, este controle existe, com certeza, por conta da Avaliação de Desempenho. Esta avaliação é uma questão delicada, porque você precisa prestar contas de tudo. (...) Com relação ao estudo e à pesquisa, o controle do Estado é grande, porque a própria dinâmica da nossa Avaliação de Desempenho tem indicadores de produtividade diferenciados para quem 
exerce ensino, extensão e pesquisa. (...) Por outro lado, do ponto de vista da condução do departamento, ele nos dá o crédito de fazer uma autoavaliação de nosso trabalho. Então, nesse sentido, você tem uma forma de autonomia. É aí que vejo que este processo tem um pouco de contradição, pois, se, por um lado, existe a regulação do Estado, por outro, a chefia concede autonomia para você fazer uma autoavaliação de seu trabalho e ver se você cumpriu as propostas da Avaliação de Desempenho. Agora, é claro que nossa nota é uma coisa e a nota que é vinda é outra, e é esta nota que gera gratificação e que incide no fator do Acordo de Resultados. Neste momento, recai de novo o controle do Estado, é quase um antagonismo. (Alice, 2011)

Fica evidente que, se, de um lado, há o controle do Estado com base nos instrumentos gerenciais de avaliação do desempenho, pautados pela lógica quantitativista (Gaulejac, 2007), de outro, os setores da universidade procuram mediar este processo, tornando-o mais significativo e menos regulado aos docentes. Todavia, a ação reguladora existe, e ela tende a se aprimorar nos próximos anos, com a necessidade de a universidade fortalecer a pós-graduação a fim de atender à exigência da Resolução CNE/CES n.o 3, de 15/10/2010, a qual estabelece como condição para o credenciamento e recredenciamento das universidades a "oferta regular de, pelo menos, quatro cursos de mestrado e dois de doutorado reconhecidos pelo Ministério da Educação (art. 3, VI)" (Brasil, 2010 , p. 2). Para isso, concorre o início de uma tendência de regular o trabalho docente e relacionar as políticas salariais e de progressão de carreira aos índices de produtividade do “Acordo de Resultados". Porém, o instrumento de avaliação de desempenho ainda pouco interfere no trabalho dos professores, sendo mero instrumento de regulação do trabalho, conforme o relato abaixo:

Acho que o Estado não controla o nosso trabalho, pois o Estado está mais preocupado se está pagando, se não está pagando, quanto está gastando. Não vejo o Estado preocupado com o trabalho da gente. Há a questão das avaliações de desempenho que o governo as instituiu através do Acordo de Desempenho. Acho que elas são fora da realidade. Sabe, muitas vezes, elas perguntam o que o Estado não te dá condições de fazer, por exemplo, a respeito de publicação, sendo que, muitas vezes, você não tem tempo para isto. Eu tenho hora para pesquisa, mas tem gente que não tem. Este tipo de avaliação é desagradável, mas eu acho que o pessoal não leva muito a sério, não. Sabe, a gente responde a eles, mas não tem muito retorno. Também não acho que os questionários que eles mandam vão alterar muito a questão da qualidade da educação. Estes questionários fazem parte da mentalidade do governo: avaliação, controle, acompanhamento. Mas não acho que isso não altera muito. Nem sei se eles estão procurando melhorar a qualidade do ensino, pois para isto têm de ouvir o professor, e não mandar formulário. (Maria, 2011) Por fim, os docentes destacam a autonomia como um aspecto positivo de seu 
trabalho na instituição, seja no sentido didático-pedagógico, seja na liberdade de expor ideias e de criar projetos:

Eu percebo que há autonomia. Pelo menos, considero que sou autônoma no meu trabalho. A gente tem autonomia, mas, de qualquer forma, tem o planejamento coletivo. Mas percebo que, de acordo com o perfil da turma, com nossa trajetória, é possível você cumprir o programa da disciplina com uma bibliografia um pouco diferente. Você pode inovar. 0 programa do curso é um ponto. Por falar nisto, o nosso próprio ponto de frequência está disponível para você assinar a hora que quiser. Então, no meu entendimento, isso é um ponto positivo, pois, a princípio, não há ninguém te regulando, pois você cumpre seu dever de maneira consciente, sem ter ninguém te controlando para ver se você veio dar aula. Acho que esta autonomia e a autonomia didática são importantes. Deixe me pensar um pouco. Em termos de pesquisa, obviamente, você tem que apresentar um relatório de produção, mas é no final da bolsa. Então, estes elementos mais básicos eu percebo que são autônomos. Eu diria que nós temos relativamente um trabalho autônomo. (Alice, 2011)

Eu tenho muita liberdade para trabalhar. Por isto, acho que autonomia até a gente tem. Mas o que não coopera muito com nosso trabalho são as próprias dificuldades institucionais de condições de trabalho, sabe? (Ana, 2011)

A autonomia de trabalho decorre do fato de a instituição e a própria universidade pública terem como característica uma espécie de descentralização das decisões em prol de uma gestão participativa e colegiada (Zabalza, 2004). Esta realidade, aliada à dimensão criativa das atividades de construção e transmissão do conhecimento científico, tem contribuído para o trabalho no magistério superior ser relativamente autônomo, ainda que parcialmente limitado pelos instrumentos de avaliação do trabalho e pela pressão por produtividade acadêmica (Silva, 2013). No entanto, a FaE/CBH/UEMG ainda não adentrou plenamente na cultura do produtivismo acadêmico, nos moldes do que ocorre nas instituições com "tradição em pesquisa". Por este motivo, os professores desta universidade não presenciam com igual intensidade os processos de regulação do trabalho e, por isto, estabelecem entre si relações mais solidárias, as quais são motivadas pelo movimento reivindicativo e construtivo do coletivo de professores.

Enfim, a satisfação decorrente da autonomia profissional e do ambiente de trabalho se fazem presentes, impulsionada pelos processos de ressignificação coletiva dos professores que buscam melhorar suas condições de trabalho e construir espaços de representação democrática na universidade. Com isto, a constituição identitária que poderia se ver "paralisada" pela insatisfação com as 
condições materiais de trabalho é reconvertida, em partes, em fator unificador do coletivo e gerador de motivação profissional. No entanto, esta reconversão não abarca todo o corpo docente e, também, não ocorre ausente de críticas e engodos.

\section{Considerações finais}

A análise dos dados apontou que o processo de construção das identidades profissionais dos professores da FaE/CBH/UEMG recebe influência de uma multiplicidade de elementos, destacando-se aqui o papel da organização de trabalho, por meio da análise de três principais elementos: as condições de trabalho, o ambiente de trabalho e a autonomia profissional.

As condições de trabalho na FaE/CBH/UEMG são caracterizadas por elementos de precariedade, tais como: baixa remuneração salarial; fragmentação da carga horária de trabalho; plano de progressão de carreira mal formulado; e infraestrutura predial verticalizada e inadequada ao funcionamento da faculdade. Tais aspectos não só revelam o sentimento de insatisfação profissional, mas criam dificuldades para a permanência do professor na UEMG e estimulam a busca de vínculos de trabalho em outras instituições, impedindo, com isto, a dedicação integral às atividades profissionais e a construção de vínculos de pertencimento institucional.

Contudo, tal precariedade impulsiona um movimento de mobilização que unifica os professores em prol de um ideal comum: melhorar as condições de trabalho e construir espaços de representação democrática na estrutura da universidade. Esta ação não só minimiza os elementos de insatisfação, mas, em certa medida, pode convertê-los, ainda que não plenamente, em satisfação profissional. Isto ocorre sobretudo porque permite ao professor ter liberdade para reinventar a organização de trabalho, construir vínculos de pertencimento institucional, de solidariedade profissional e obter um reconhecimento profissional, aspectos que são centrais na construção de uma identidade profissional.

Associado a isso, a pesquisa apontou também o sentimento de autonomia profissional e de satisfação com o ambiente de trabalho por parte dos docentes, em um contexto universitário em que a cultura da avaliação heterônoma e do produtivismo acadêmico ainda não se efetivaram plenamente, propiciando condições de se ter um trabalho relativamente mais autônomo e relações profissionais mais solidárias.

Diante desta situação, a construção das identidades se apresenta a partir de uma relação dialética e, por vezes, contraditória entre aspectos de satisfação e insatisfação profissional. Por fim, reitera-se, ainda, o caráter transitório dessas 
construções identitárias, que no futuro poderão ser alteradas em face do atual dinamismo do ensino superior, das recentes melhorias salariais e de progressão de carreira, e do atual contexto de instabilidade proveniente do julgamento do STF em 26/03/2014 de inconstitucionalidade da Lei Complementar n. ${ }^{0} 100$, de 05/11/2007. Salienta-se, por isto, a importância de futuras pesquisas, a fim de acompanhar as possíveis alterações no trabalho e na constituição identitária decorrente das novas transformações vivenciadas na universidade.

\section{Referências}

ANA. Entrevista oral. Belo Horizonte, 29 out. 2011.

ALICE. Entrevista oral. Belo Horizonte, 02 nov. 2011.

BARDIN, Laurence. Análise de Conteúdo. Lisboa: Edições 70, 2009.

BERGER, Peter Ludwig; LUCKMANN, Thomas. A construção social da realidade. Trad. Floriano de Souza Fernandes. Petrópolis: Vozes, 2002.

BOSI, Antônio de Pádua. A precarização do trabalho docente nas instituições de ensino superior do Brasil nesses últimos 25 anos. Educação e Sociedade, Campinas, v. 28, n.101, pp. 1503-1523, set/dez. 2007. Disponível em: <http://www.scielo.br/ pdf/es/v28n101/a1228101>. Acesso em: 5 abr. 2013.

BRASIL. Conselho Nacional de Educação. Câmara de Educação Superior. Resolução CNE/CES nº 3 de 14 de outubro de 2010. Diário Oficial da União, Brasília, 2010 Seção 1 - p. 10. Disponível em: <http://portal.mec.gov.br/index.php?option=com_ content\&view=article\&id=14917\&ltemid=866>. Acesso em: 13 fev. 2011.

DEJOURS, Christophe. 0 trabalho como enigma. In: LANCMAN, Selma.; SZNELWAR, Laerte. (Org.). Christophe Dejours: da psicopatologia à psicodinâmica do trabalho. Brasília: Paralelo 15 / Rio de Janeiro: Editora Fiocruz, 2004. pp. 127-140.

Inteligência prática e sabedoria prática: duas dimensões desconhecidas do trabalho real. In: LANCMAN, Selma; SZNELWAR, Laerte. (Orgs). Christophe Dejours: da psicopatologia à psicodinâmica do trabalho. Brasília: Paralelo 15 / Rio de Janeiro: Editora Fiocruz, 2004a. pp. 277-299.

DUBAR, Claude. A socialização: construção das identidades sociais e profissionais. Trad. Andréa Stahel Monteiro da Silva. São Paulo: Martins Fontes, 2005.

FLICK, Uwe. Uma introdução à pesquisa qualitativa. Trad. Sandra Netz. Porto Alegre: Bookman, 2004.

GAULEJAC, Vincent. Gestão como doença social: ideologia, poder gerencialista e fragmentação social. Aparecida, São Paulo: Ideias \& Letras, 2007.

MARIA. Entrevista oral. Belo Horizonte, 22 nov. 2011

MATTOS, Maria do Carmo de. Formação docente e integração curricular: proposta 
do Curso de Pedagogia da Faculdade de Educação/UEMG. 2009. 229 f. Tese (Doutorado em Educação) Faculdade de Educação, Universidade do Estado Rio de Janeiro, Rio de Janeiro, 2009.

MAUÉS, Olgaíses Cabral; MOTA JÚNIOR, Willian Pessoa da. A nova regulação educacional e o trabalho docente na pós-graduação brasileira. Linhas Críticas, v.17, n.33, pp. 385-402, maio/ago. 2011. Disponível em: <http://seer.bce.unb.br/ index.php/linhascriticas/article/view/5700/4712>. Acesso em: 20 out. 2013.

MINAS GERAIS. Lei complementar 100, de 05 de novembro de 2007. Belo Horizonte, 2007. Disponível em: <http://www.almg.gov.br/consulte/legislacao/completa/ completa.html?tipo=LCP\&num=100\&ano=2007>. Acesso em: 7 out. 2010.

. Decreto 46.024, de 16 de agosto de 2012. Belo Horizonte, 2012. Disponível em: <http://www.almg.gov.br/consulte/legislacao/completa/completa.html?tipo= DEC\&num $=46024 \&$ comp $=\& a n o=2012>$. Acesso em: 15 out. 2012.

Decreto 46.056, de 3 de outubro de 2012. Belo Horizonte, 2012. Disponível em: <http://www.almg.gov.br/consulte/legislacao/completa/completa.html?tipo $=\mathrm{DEC} \&$ num $=46056 \& \mathrm{comp}=\& a n o=2012 \& a b a=j s \_t$ textoOriginal \#texto $>$ Acesso em: 15 out. 2012.

Lei 20.336, de 2 de agosto de 2012. Belo Horizonte, 2012. Disponível em: <http://www.almg.gov.br/consulte/legislacao/completa/completa-nova-min.html ?tipo $=$ LEl $\&$ num $=20336 \&$ comp $=\& a n o=2012 \&$ texto=original $\#$ texto $>$. Acesso em: 15 out. 2012.

Lei 20.591, de 28 de dezembro de 2012. Belo Horizonte, 2012. Disponível em: <http://www.almg.gov.br/consulte/legislacao/completa/completa.html?tipo= LEI\&num=20591\&comp=\&ano=2012>. Acesso em: 10 jan. 2013.

MOREIRA, Antônio Flávio. A cultura da performatividade e a avaliação da PósGraduação em Educação no Brasil. Educação em Revista, Belo Horizonte, v. 25, n. 3, pp.23-42, dez. 2009. Disponível em: <http://www.scielo.br/pdf/edur/v25n3/03. pdf>. Acesso em: 01 dez. 2013.

PATRÍCIA. Entrevista oral. Belo Horizonte, 21 nov. 2011.

PAULA. Entrevista oral. Belo Horizonte, 15 nov. 2011.

QUESTIONÁRIO. Relato dissertativo do questionário. Belo Horizonte, 13 jun. 2011. RUZA, Fábio Machado; SILVA, Santuza Amorim da; PÁDUA, Karla Cunha. A identidade no e pelo trabalho: elementos constituintes das identidades profissionais dos professores da FaE/CBH/UEMG. Perspectiva, Florianópolis, v. 31, n.3, pp. 1099-1129, set/dez. 2013. Disponível em: <https://periodicos.ufsc.br/ index.php/perspectiva/article/view/2175-795X.2013v31n3p1099/27736>. Acesso em: 08 out. 2014.

SGUISSARDI, Valdemar; SILVA JÚNIOR, João dos Reis. Trabalho intensificado nas federais: pós-graduação e produtivismo acadêmico. São Paulo: Xamã, 2009. 
SILVA, Eduardo Pinto e. Sofrimento psíquico no trabalho do professor da universidade pública. In: FREITAS, Lêda Gonçalves de (Coord.) Prazer e sofrimento no trabalho docente: pesquisas brasileiras. Curitiba: Juruá, 2013. pp. 71-92.

SILVA, Joseli Maria; SILVA, Armando; JUNCKES, Ivan Jairo. Construindo a ciência: elaboração crítica de projetos de pesquisa. Curitiba: Pós-Escrito, 2009.

SILVA, Santuza Amorim; PÁDUA, Karla Cunha. Explorando narrativas: algumas reflexões sobre suas possibilidades na pesquisa. In: CAMPOS, Regina Celia Passos Ribeiro de. Pesquisa, Educação e Formação Humana: nos trilhos da História. Belo Horizonte: Editora Autêntica, 2010. pp. 105-135.

VILHENA, Renata; MARTINS, Humberto Falcão; MARINI, Caio. Introdução. In: VILHENA, Renata; MARTINS, Humberto Falcão; MARINI, Caio; GUIMARÃES, Tadeu Barreto. (Orgs). O Choque de Gestão em Minas Gerais: Políticas da Gestão Pública para o Desenvolvimento. Belo Horizonte: Editora UFMG, 2006.

YIN, Robert. Ken. Estudo de caso: planejamento e métodos. Trad. Daniel Grassi. 3. ed. Porto Alegre: Bookman, 2005.

ZABALZA, Miguel. Ângelo. 0 ensino universitário: seu cenário e seus protagonistas. Trad. Ernani Rosa. Porto Alegre: Artmed, 2004.

Recebido em julho de 2014 Aprovado em dezembro de 2014

Fábio Machado Ruza é mestre em educação pela Universidade do Estado de Minas (UEMG) Gerais e doutorando em educação pela Universidade Federal de São Carlos. E-mail: fabioruzadyahoo.com.br

Santuza Amorim da Silva é doutora em educação pela Universidade Federal de Minas Gerais (UFMG) e professora do Programa de Pós-Graduação em Educação da Universidade do Estado de Minas Gerais (UEMG). E-mail: santuzalahotmail.com

Karla Cunha Pádua é doutora em educação pela Universidade Federal de Minas Gerais (UFMG), pós-doutorado (2013) na área de antropologia, no Instituto de Ciências Sociais (ICS) da Universidade de Lisboa, e professora do Programa de Pós-Graduação em Educação da UEMG. E-mail: kcpaduadyahoo.com.br 